\title{
Bone Marrow Stromal Cells Promote Neuronal Restoration in Rats with Traumatic Brain Injury: Involvement of GDNF Regulating BAD and BAX Signaling
}

\author{
Qin Shen ${ }^{a}$ Yong Yin ${ }^{b}$ Qing-Jie Xiac Na Lin ${ }^{a}$ You-Cui Wang ${ }^{c}$ Jia Liu ${ }^{a}$ \\ Hang-Ping Wang ${ }^{d}$ Apiradee Lim ${ }^{\mathrm{e}}$ Ting-Hua Wang ${ }^{\mathrm{a}, \mathrm{c}, \mathrm{d}}$
}

\begin{abstract}
Institute of Neuroscience, Faculty of Basic Medicine, Kunming Medical University, Kunming, China; bDepartment of Rehabilitations, No. 4 Affiliated Hospital of Kunming Medical University, Kunming, China; 'Institute of Neurobiological Disease, Translational Neuroscience Center and the State Key Laboratory of Biotherapy, West China Hospital, Sichuan University, Chengdu, China; dSchool of Sports,

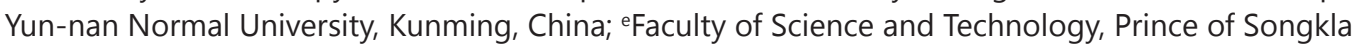
University, Pattani Campus, Songkhla, Thailand
\end{abstract}

\section{Key Words}

Bone marrow stromal cells $•$ Traumatic brain injury $\bullet$ Glial cell-line derived neurotrophic factor - BAX • BAD

\footnotetext{
Abstract

Background/Aims: To investigate the effects of bone marrow stromal cells (BMSCs) and underlying mechanisms in traumatic brain injury (TBI). Methods: Cultured BMSCs from green fluorescent protein-transgenic mice were isolated and confirmed. Cultured BMSCs were immediately transplanted into the regions surrounding the injured-brain site to test their function in rat models of TBI. Neurological function was evaluated by a modified neurological severity score on the day before, and on days 7 and 14 after transplantation. After 2 weeks of BMSC transplantation, the brain tissue was harvested and analyzed by microarray assay. And the coronal brain sections were determined by immunohistochemistry with mouse antigrowth-associated protein-43 kDa (anti-GAP-43) and anti-synaptophysin to test the effects of transplanted cells on the axonal regeneration in the host brain. Terminal deoxynucleotidyl transferase-mediated dUTP nick end labeling (TUNEL) assay and Western blot were used to detect the apoptosis and expression of BAX and BAD. Results: Microarray analysis showed that BMSCs expressed growth factors such as glial cell-line derived neurotrophic factor (GDNF). The cells migrated around the injury sites in rats with TBI. BMSC grafts resulted in an increased number of GAP-43-immunopositive fibers and synaptophysin-positive varicosity, with suppressed apoptosis. Furthermore, BMSC transplantation significantly downregulated the expression of BAX and BAD signaling. Moreover, cultured BMSC transplantation significantly improved rat neurological function and survival. Conclusion: Transplanted BMSCs could

T.-H. Wang and A. Lim contribute equally to this work.

\begin{tabular}{ll}
\hline Ting-Hua Wang \\
and Apiradee Lim
\end{tabular}$\quad \begin{aligned} & \text { Institute of Neuroscience, Faculty of Basic Medicine, Kunming Medical University, } \\
& \text { Kunming 650031, (China); and Faculty of Science and Technology, Prince of Songkla } \\
& \text { University, Pattani Campus, 646400, (Thailand) } \\
& \text { Tel. +86-28-85501036, E-Mail tinghuawang263@sina.com E-Mail api_45@hotmail.com }\end{aligned}$
}




\section{Cellular Physiology Cell Physiol Biochem 2016;38:748-762

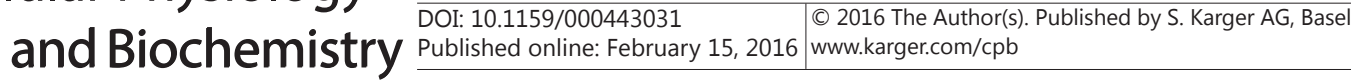 \\ Shen et al.: BMSCs Promote Neuronal Restoration in Rats}

survive and improve neuronal behavior in rats with TBI. Mechanisms of neuroprotection and regeneration were involved, which could be associated with the GDNF regulating the apoptosis signals through BAX and BAD.

\section{Introduction}

Traumatic brain injury (TBI) is a leading cause of mortality and morbidity in the world, since it induces degeneration and death of cells of the central nervous system. According to an epidemiological study in China, traffic accidents and falls from height are the primary causes of TBI $(60.9 \%$ and $13.4 \%$, respectively) [1]. For all patients with TBI, the mortality rate is still high at $10.8 \%$, while $2.6 \%$ remain in a persistent vegetative state, $2.2 \%$ have severe disabilities, and $7.2 \%$ have moderate disabilities [2]. Even higher rates of mortality and disability are observed in Asian countries with low or middle income [3]. Currently, few interventions have been shown to be efficacious for the treatment of TBI in clinical trials [4], and it is therefore necessary to develop new therapeutic interventions for the clinical treatment of TBI.

The pathophysiological process of TBI includes primary and secondary response phases [5]. The pathological cascade is associated with changes in a number of genes such as neurotrophic growth factors, and therapeutic strategies for TBI mainly include the administration of neurotrophic drugs and rehabilitation training of neurological function [6]. However, tissue or cellular transplantation is now considered as one of the most promising strategies for the therapy of TBI [7-9]. There is growing evidence that transplantation of bone marrow stromal cells (BMSCs) can be useful in reversing the sequels of trauma affecting the brain and/or the spinal cord. BMSCs have distinct biological features that support the survival and development of neurons [10] and promote axonal regeneration [11]. BMSCs are stromal cells and are present in the femur and tibia [12]. They share some features with Schwann cells and astrocytes [13]. BMSCs can release neurotrophic factors (NFs) such as nerve growth factor (NGF), brain-derived neurotrophic factor (BDNF), glial cell-line derived neurotrophic factor (GDNF), and neurotrophin (NT) to support the survival and development of neurons [14-16]. Based on the capacity of BMSC for self-renewal and differentiation into target cells [17], BMSCs could be used for treating TBI. Therefore, the aim of the present study was to examine the effects of BMSCs on neural behavior and the involvement of GDNF, $\mathrm{BAX}$, and BAD signaling in this process. The results could provide critical evidence for the therapy of TBI using BMSC transplantation for future clinical trials.

\section{Materials and Methods}

Culturing, purification, and identification of BMSCS

The BMSCs were harvested from 6- to 8-week-old green fluorescent protein-transgenic mice (Center of Experimental Animal, Kunming Medical University, Kunming, China), and were isolated as described in a previous study [18]. Briefly, both ends of the femur and tibia were cut, and the marrow was flushed using Dulbecco's Modified Eagle Medium Nutrient Mixture F-12 (DMEM/F-12; Gibco, NY, USA). Then, the marrow was mechanically dissociated into a single-cell suspension. Cells were cultured in DMEM/F-12, supplemented with 10\% fetal bovine serum (Gibco) and 2mM glutamine, 10,000 U/L penicillin, and 10 $\mathrm{mg} / \mathrm{L}$ streptomycin. The flasks were cultured in a standard humidified air incubator containing $5 \% \mathrm{CO}_{2}$ and maintained at $37^{\circ} \mathrm{C}$. When the adherent cells grew to $90 \%$ confluence, they were passaged (1:3) into different culture flasks. BMSCs at passage 2 were used for the study. After approximately 21 days, the cells were either transplanted or plated onto poly-L-lysine-coated glass cover slips or plastic culture dishes at a density of $10^{5}$ cells $/ \mathrm{mL}$. For immunofluorescence, BMSCs were incubated continuously for 12 hours, fixed in $4 \%$ paraformaldehyde for 20 minutes, and washed with phosphate-buffered saline (PBS) three times. Cells were permeabilized and preincubated with blocking solution (containing $2 \%$ goat serum, $0.3 \%$ Triton $\mathrm{X}-100$, and $0.1 \%$ BSA in PBS) for 30 minutes at room temperature. Then, they were incubated overnight 


\section{Cellular Physiology Cell Physiol Biochem 2016;38:748-762

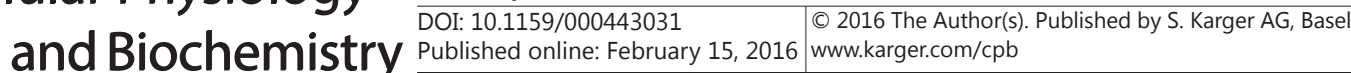 \\ Shen et al.: BMSCs Promote Neuronal Restoration in Rats}

with a primary antibody (CD44; 1:200; Millipore Bioscience Research Reagents, CA, USA) diluted in the same blocking solution at $4^{\circ} \mathrm{C}$, washed with PBS, and incubated with Cy3-conjugated goat anti-rabbit IgG (red) secondary antibody diluted in the same blocking solutions for 30 minutes at $37^{\circ} \mathrm{C}$. Cells were observed with a light microscope (Leica, Solms, Germany) to identify the cells and to determine the purity of BMSCs. Flow cytometry was used to examine the BMSCs accurately. BMSCs were labeled with mouse MSC positive cocktail, as described in a previous study [19]. Cells were analyzed using a BD Aria flow cytometry system (BD Biosciences, NJ, USA). Briefly, BMSCs were labeled by mouse MSC positive cocktail: CD90 FITC (Clone: 5E10); CD105PerCP-Cy5.5 (Clone: 266); CD73 APC (Clone: AD2); and PE mouse BMSC negative cocktail: CD34 PE (Clone: 581); CD45 PE (Clone: HI30); and HLA-DR PE (Clone: G46-6). Then cells were detached using BD Accutase Cell Detachment Solution (No. 561527), washed and resuspended at a concentration of $1 \times 10^{7}$ cells/mL in BD Pharmingen Stain Buffer (No. 554656) for test, and followed the assay procedure: The tubes were labeled and antibodies added (the kit components of flow cytometry description as in Table 1); this was repeated for each additional cell sample; tubes were then incubated in the dark for 30 minutes; the cells were washed twice with BD Pharmingen Stain Buffer (FBS) and resuspended at $300-500 \mu \mathrm{L}$ in BD Pharmingen Stain Buffer (FBS); the cells were then analyzed using a BD Aria flow cytometry system.

\section{Immunofluorescence}

Cultured BMSCs were washed in PBS for 10 minutes in 96-well plates and then blocked in 5\% normal goat serum for 30 minutes. This was followed by incubation in 0.3\% Triton X-100 in PBS for 30 minutes at room temperature. Afterward, the BMSCs were incubated with rabbit anti-GDNF (1:500; Santa Cruz Biotechnology, CA, USA) for 2 hours at $37^{\circ} \mathrm{C}$ and then overnight at $4^{\circ} \mathrm{C}$. After washing three times and incubating with fluorescent secondary antibody IgG (1:200, Cy3-conjugated goat anti-rabbit IgG: red; Santa Cruz Biotechnology) for 2 hours at $37^{\circ} \mathrm{C}$, red fluorescence was observed under fluorescence microscopy. The pictures were collected using a Leica imagine analysis system (Leica, IL, USA).

\section{TBI modeling}

The animal research process conformed to the relevant ethical guidelines for human and animal research. All protocols involving the use of animals complied with the National Institutes of Health Guide for the Care and Use of Laboratory Animals, and were approved by the Animal Care and Use Committee, Kunming Medical University (Kunming, China). Forty-eight healthy Sprague-Dawley (SD) rats weighing 200 $\pm 20 \mathrm{~g}$ were used in the study. They were randomly assigned to three groups ( $n=16$ per group): the shamoperated group; the TBI group (underwent injury in the cortical motor area); and the BMSC transplantation group (BMSCs were implanted into the injured site). Three days before operation and daily after operation, all rats were injected intraperitoneally (i.p.) with cyclosporine A $(1 \mathrm{mg} / \mathrm{kg} /$ day). All rats were injected with the same medium as the rats in the BMSC group.

A modified controlled cortical impact device (VA, USA) was used to administer unilateral brain injury based on the modified Feeney method [20]. Briefly, rats were anesthetized with chloral hydrate (360 mg/

Table 1. The Kit Components Description

\begin{tabular}{|c|c|c|}
\hline Vial & Contents & Purpose \\
\hline mouse MSC Positive Cocktail & $\begin{array}{l}\text { CD90 FITC (Clone: 5E10); } \\
\text { CD105 PerCP-Cy5.5 (Clone: 266); } \\
\text { CD73 APC (Clone: AD2); }\end{array}$ & Cocktail to positively identify mouse BMSCs \\
\hline $\begin{array}{l}\text { mouse BMSC Positive Isotype Control } \\
\text { Cocktail }\end{array}$ & 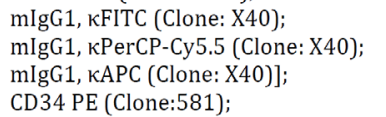 & $\begin{array}{l}\text { Corresponding Isotype Control for Positive Cocktail } \\
\text { Cocktail }\end{array}$ \\
\hline PE mouse BMSC Negative Cocktail & $\begin{array}{l}\text { CD } 45 \text { PE (Clone: HI30); } \\
\text { HLA-DR PE (Clone: G46-6). }\end{array}$ & Cocktail to identify potential contaminants \\
\hline $\begin{array}{l}\text { PE hMSC Negative Isotype Control } \\
\text { Cocktail }\end{array}$ & $\begin{array}{l}\text { mIgG1,кPE (Clone: X40); } \\
\text { mIgG2a, кPE (Clone:G155-178 }\end{array}$ & \multirow{2}{*}{$\begin{array}{l}\text { Corresponding isotype control for PE BMSC) Negative } \\
\text { Cocktail } \\
\text { Compensation control }\end{array}$} \\
\hline FITC rate Anti-mouse CD90 & CD90 FITC (Clone: 5E10) & \\
\hline PerCP-Cy ${ }^{\mathrm{TM}} 5.5$ rat Anti-mouse & $\begin{array}{l}\text { CD105 CD105 PerCP-Cy }{ }^{\mathrm{TM}} 5.5 \text { (Clone: } \\
\text { 266) }\end{array}$ & Compensation control \\
\hline $\mathrm{APC}$ rat Anti-mouse CD73 & CD73 APC (Clone:AD2) & Compensation control \\
\hline $\mathrm{PE}$ rat IgG2b, $\kappa$ Isotype Control & mIgG2b, א(Clone: 27-35) & Corresponding Isotype control \\
\hline
\end{tabular}




\section{Cellular Physiology Cell Physiol Biochem 2016;38:748-762

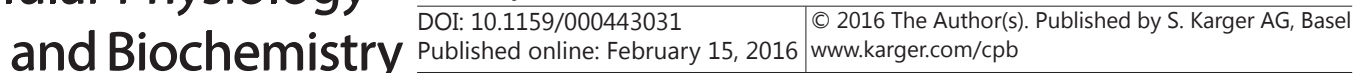 \\ Shen et al.: BMSCs Promote Neuronal Restoration in Rats}

$\mathrm{kg}$, i.p.). The head was mounted in a stereotaxic frame and held in the horizontal plane. A midline incision was made for exposure, and a 7- to 8-mm craniectomy was performed on the right cranial vault. The center of the craniectomy was placed at the midpoint between bregma and lambda, 3-mm lateral to the midline, overlying the tempoparietal cortex. Animals received a single impact of 3.1-mm depth of deformation with an impact velocity of $6 \mathrm{~m} / \mathrm{second}$ and a dwell time of $150 \mathrm{~ms}$ (moderate-severe injury) at an angle of $10^{\circ}$ from the vertical plane with the use of a 6-mm-diameter impact tip, making the impact orthogonal to the surface of the cortex. An audible baseline monitor was used to ensure that the location of the tip was consistent before each impact, relative to the surface of the brain. The impact was delivered onto the parietal association cortex. Sham injury was performed by anesthetizing the animals, making the midline incision, and separating the skin, connective tissue, and aponeurosis from the cranium before closing the incision. The body temperature was maintained at $37^{\circ} \mathrm{C}$ using a heating pad [21].

\section{Preparation of cellular suspension and transplantation}

BMSCs from three passages were harvested. After TBI, BMSCs were immediately transplanted into the rats (BMSC transplantation group) in the pericontusional region using a cell density of $1 \times 10^{7} / \mathrm{mL}$. For transplantation, a 25 -gauge microinjection needle was used to stereotactically guide the placement of the cells into the area of injury and the penumbral area. Cellular suspensions ( $5 \mu \mathrm{L})$ were injected at four sites: 3-mm rostral, caudal, left, and right from the center of the injured site. For each site, the cell suspension was delivered at three depth points $(2,1.5$, and $1 \mathrm{~mm})$ from the surface of the cortex [22, 23]. The injection velocity was controlled at $1 \mu \mathrm{L} / \mathrm{min}$. The volume of the injected cell suspension was $1.5 \mu \mathrm{L}, 2 \mu \mathrm{L}$, and $1.5 \mu \mathrm{L}$, respectively. After each injection, the needle was held in for 1 minute before being withdrawn. Animals in the TBI group underwent identical procedures, with the injections only consisting of the DMEM/F12 medium without BMSCs. After the surgical incisions were sutured, the rats received extensive postoperation care such as penicillin $(50,000 \mathrm{U} / \mathrm{kg} /$ day, i.p.) for 3 days.

\section{Neurological behavior}

Neurological function was evaluated by a modified neurological severity score (NSS) [24] on the day before, and on days 7 and 14 after the transplantation. The evaluations consisted of motor (muscle status and abnormal movement), sensory (visual, tactile, and proprioceptive), reflex, and balance tests, and were recorded on a scale of 0-18 (normal score, 0 ; maximal deficit score, 18). They were performed by blinded, trained observers. For the NSS, one point was scored for inability to perform the test or the lack of a tested reflex. Thus, a high score indicated severe injury. All rats were given enough time to become familiar with the testing environment before inflicting the brain injury. This was assessed by the rat's ability to perform all the tests, and then an NSS was performed.

\section{Microarray analysis}

To determine the expression of different genes in the brains of rats with TBI and with TBI plus BMSC transplantation, microarray analysis from Agilent's whole rat genome (service provided by Kangchen Biotech, Shanghai, China) was performed to survey the gene expression map. The results were extracted using the Agilent Feature Extraction Software (version 9.5.3), then imported into the Agilent Gene Spring GX software (version 7.3) for further analysis. Consequently, differentially expressed genes (twofold change) were identified.

\section{BMSC survival and migration}

Following the BMSC transplantation, coronal brain sections were obtained after 2 weeks for detecting the survival and migration of transplanted BMSCs. After chloral hydrate injections ( $360 \mathrm{mg} / \mathrm{kg}$, i.p.), the thoracic cavity was opened and room-temperature normal saline was infused for 5 minutes via the left ventricle. Animals were exsanguinated using the right atrium puncture. Then, cold $4 \%$ paraformaldehyde was perfused for 15 minutes via the left ventricle. The brain was extracted and placed in $4 \%$ paraformaldehyde at $4^{\circ} \mathrm{C}$ for $24-48$ hours and then placed in $30 \%$ sucrose solution overnight at $4^{\circ} \mathrm{C}$ for cryoprotection after dehydration in a 15\% sucrose solution for 8 hours. The brains were embedded in OCT compound (Sakura Finetec, CA, USA) and cut into $20-\mu \mathrm{m}$-thick sections. The sections were placed on the slides and viewed using a fluorescence microscope (DM I6000B, Leica, Wetzlar, Germany). The number of surviving cells was assessed from four fields surrounding the epicenter. To detect the proliferation of the transplanted cells, Ki67 (a marker) was detected using a rabbit anti-Ki67 antibody (Abcam, MA, USA) and Cy3-conjugated KARGER 


\section{Cellular Physiology Cell Physiol Biochem 2016;38:748-762 \begin{tabular}{l|l|l|l} 
DOI: 10.1159/000443031 & $\begin{array}{l}\text { @ } 2016 \text { The Author(s). Published by S. Karger AG, Basel } \\
\text { www.karger.com/cpb }\end{array}$
\end{tabular} \\ Shen et al.: BMSCs Promote Neuronal Restoration in Rats}

goat anti-rabbit IgG secondary antibody (red). The slides were observed using a florescence microscope. Proliferating cells were counted from four fields surrounding the epicenter.

Immunohistochemistry for axonal regeneration

Rats were anesthetized and tissues were processed after TBI. A total of $500 \mathrm{~mL}$ of $0.1 \mathrm{M}$ PBS (pH, 7.2-7.3, room temperature) was injected into the left ventricle for 20-30 minutes, followed by $500 \mathrm{~mL}$ of $4 \%$ paraformaldehyde in $0.1 \mathrm{M}$ PBS ( $\mathrm{pH} 7.2-7.3,4^{\circ} \mathrm{C}$ for 1 hour) for TUNEL assay and immunostaining. The brain was removed and immersed in the same fixative at $4^{\circ} \mathrm{C}$ for 24 hours and transferred into the PBS containing $30 \%$ sucrose before cryosectioning. Serial sections of the brain tissues were sliced at a thickness of $20 \mu \mathrm{m}$ using a cryotome (CM1900, Leica), and mounted on gelatin-pretreated slides. To test the effects of transplanted cells on the axonal regeneration in the host brain, the expression of growth-associated protein-43 kDa (GAP-43) in the coronal brain sections was determined by immunohistochemistry with mouse anti-GAP-43 (Chemicon, CA, USA) and horseradish peroxidase (HRP)-labeled secondary antimouse antibody (Dako, Glostrup, Denmark). Bound antibodies were visualized with 3, 3-diaminobenzidine tetrahydrochloride (Dako) by means of the avidin-biotin peroxidase complex method, according to the standard protocols (Vector Laboratories, CA, USA). Images were captured on an Axio Observer Microscope Z1 using the AxioVision 4.6 software system (Carl Zeiss GmbH, Oberkochen, Germany) at a magnification of $20 \times$ and $40 \times$. Two sections from the anterior injury, anterior penumbra, central injury, posterior injury, and posterior penumbra areas of each brain were viewed. Cells per coronal section were counted and the counts were averaged and extrapolated to the entire injury area $(8 \mathrm{~mm})$ and brain. Five slices in each group and five visual fields at $400 \times$ were used to count the number of GAP-43-positive axons and synaptophysinpositive varicosity [25].

\section{Host neuronal apoptosis}

To detect apoptotic neurons in the host brain, TUNEL staining was performed in accordance with the manufacturer's instructions (Roche K-X, Biotechnology, Shanghai, China). A previous study reported two distinct patterns of apoptosis [26]. Some cells were densely labeled and showed clear apoptotic characteristics, such as perinuclear ring formation, patches, or an apoptotic body. Other cells were weakly labeled and considered to be necrotic cells. Only the densely labeled cells were counted as TUNEL-positive cells [27]. To compare the number of apoptotic cells, three fields (400x) from each brain section of each rat in each group were used for statistical analysis.

\section{Western blotting}

Tissue samples were lysed, homogenized in RIPA lysis buffer (Beyotime, Jiangsu, China) containing 2\% of protease inhibitor cocktail (Roche K-X, Biotechnology), and centrifuged at 12,000 g for 15 minutes at $4^{\circ} \mathrm{C}$. The supernatant was collected, and the protein concentration was determined by the BCA assay (Beyotime). T Primary antibodies against GDNF (Abcam), BAX (Epitomic, CA, USA), Bad (Epitomic), and $\beta$-actin (Sigma, MO, USA) were used. The secondary antibody was goat anti-rabbit IgG (ZSGB-BIO, Beijing, China). The blots were scanned using an Alpha Innotech scanner (Bio-Rad, CA, USA) using electrochemiluminescence. $\beta$-actin was used as the internal control.

\section{Reverse transcription-polymerase chain reaction}

Total RNA from fibroblast and BMSCs cells was extracted using a commercial kit (Fermentas, Burlington, ON, Canada), according to the manufacturer's instructions. For reverse transcription, $2.0 \mu \mathrm{g}$ RNA per sample was reversely transcribed using a reverse transcription kit (Kontes Thomas Scientific, NJ, USA), according to the manufacturer's instructions. Primers for Gdnf and $\beta$-Actin (as an internal control) were designed with the primer 5.0 software and are shown in Table 2.

\section{Statistics}

Statistical analysis was performed using the SPSS 16.0 software (SPSS Inc., IL, USA). Continuous data were expressed as mean \pm standard deviation

Table 2. Primers for RT-PCR

\begin{tabular}{lll}
\hline Genes & Primers $\left(5^{\prime}-3^{\prime}\right)$ & Length (bp) \\
\hline Gdnf & $\begin{array}{l}\text { ATGAAGTTATGGGATGTCGTGG } \\
\text { GCCGCTTGTTTATCTGGTGA }\end{array}$ & \\
\multirow{3}{*}{-Actin } & $\begin{array}{l}\text { GTAAAGACCTCTATGCCAACA } \\
\text { GGACTCATCGTACTCCTGCT }\end{array}$ & \\
& 227 \\
\hline
\end{tabular}




\section{Cellular Physiology Cell Physiol Biochem 2016;38:748-762

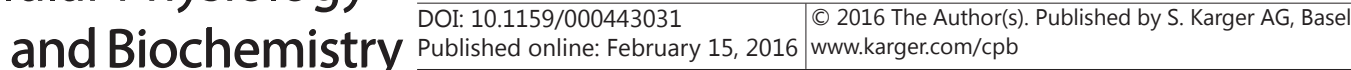 \\ Shen et al.: BMSCs Promote Neuronal Restoration in Rats}

and were analyzed using one-way analysis of variance with the Student-Newman-Keuls post-hoc $t$-test. Two-sided $P$ values $<0.05$ were considered statistically significant.

\section{Results}

\section{Successful isolation of BMSCs}

After the second passage, cultured cells began to increase in number and size, and acquired the characteristics of BMSCs. At 5 days, three kinds of relatively classical cells derived from BMSCs appeared in the medium, with bipolar, multipolar, and oblate shapes. At this stage, the morphology of BMSCs was distinct, three-dimensional, with strong brightness. BMSCs were mainly bipolar and multiapophysis and interlaced into networks (Fig. 1A). Then, immunofluorescence was used to identify the BMSCs. A large number of bipolar and multipolar BMSCs were positive for CD44, which was located both in the cytoplasm and processes (Fig. 1B). For tracing BMSCs in vivo, green fluorescent protein emitting from BMSCs was followed (Fig. 1C). For flow cytometry, cells were characterized for the expression of a set of cell-surface markers (CD34, CD 45, CD73, CD105, and CD90) (Fig. 1D-K). Cells were negative for CD45 and CD34 (Fig. 1D), and positive for CD73, CD105, and CD90 (Fig. 1E and F). Figure $1 \mathrm{G}$ presents the percentage of marked cells.

Expression of GDNF significantly increased in the brains of rats with BMSC transplantation

A microarray analysis showed that more than 5100 genes exhibited differential expression in the brain of rat between TBI and TBI plus BMSC transplantation. Among these genes, genes for NF in the brains of rat were substantially upregulated in the TBI plus BMSC transplantation group compared with the TBI group (Fig. 2A). Importantly, GDNF was substantially upregulated in the brain of rat with BMSC transplantation (Fig. 2B). According
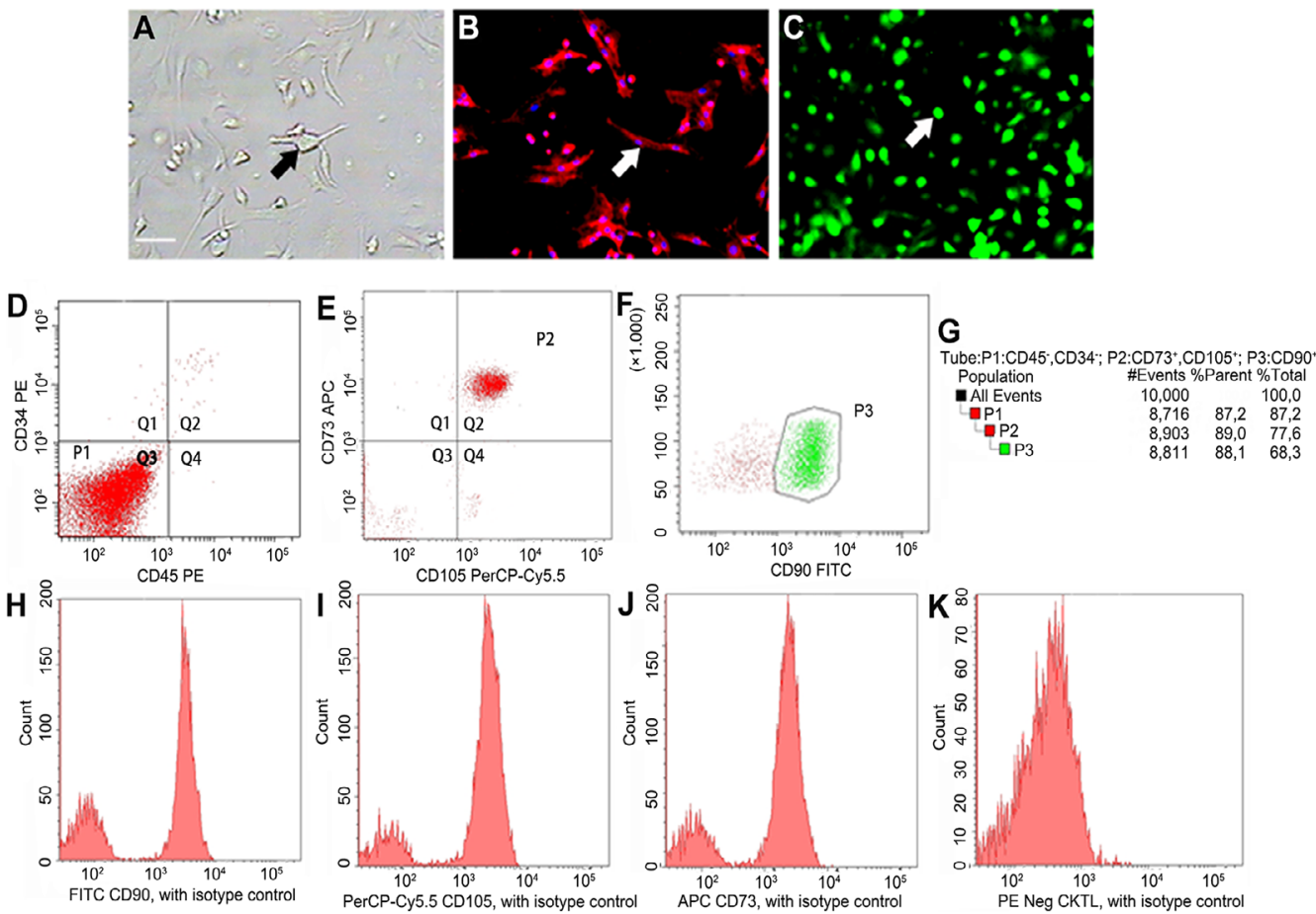

Fig. 1. Morphology of BMSCs in vitro. (A) BMSCs (arrow) presented bipolar and multipolar morphology with a three-dimensional interlaced network. (B) Positive staining for CD44. (C) BMSC harvested from green fluorescent protein-transgenic mice emitted green fluorescence. Scale bars: $50 \mu \mathrm{m}$. (D-K) Flow cytometry showed the cellular expression of a set of cell-surface markers (CD34, CD 45, CD73, CD105, and CD90). 


\section{Cellular Physiology Cell Physiol Biochem 2016;38:748-762

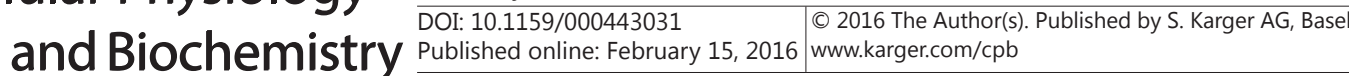

Fig. 2. Microarray analysis of neurotrophic factor gene expression in vivo. (A) Heat diagram of differential expression of neurotrophic factors (NFs) in the brain of rat with TBI (TBI) and with TBI plus BMSCs transplantation (TBI + BMSCs). (B) Histogram of differential NF genes. (C) The GDNF protein levels in TBI and TBI + BMSCs. (D) Quantification of Western blotting results.

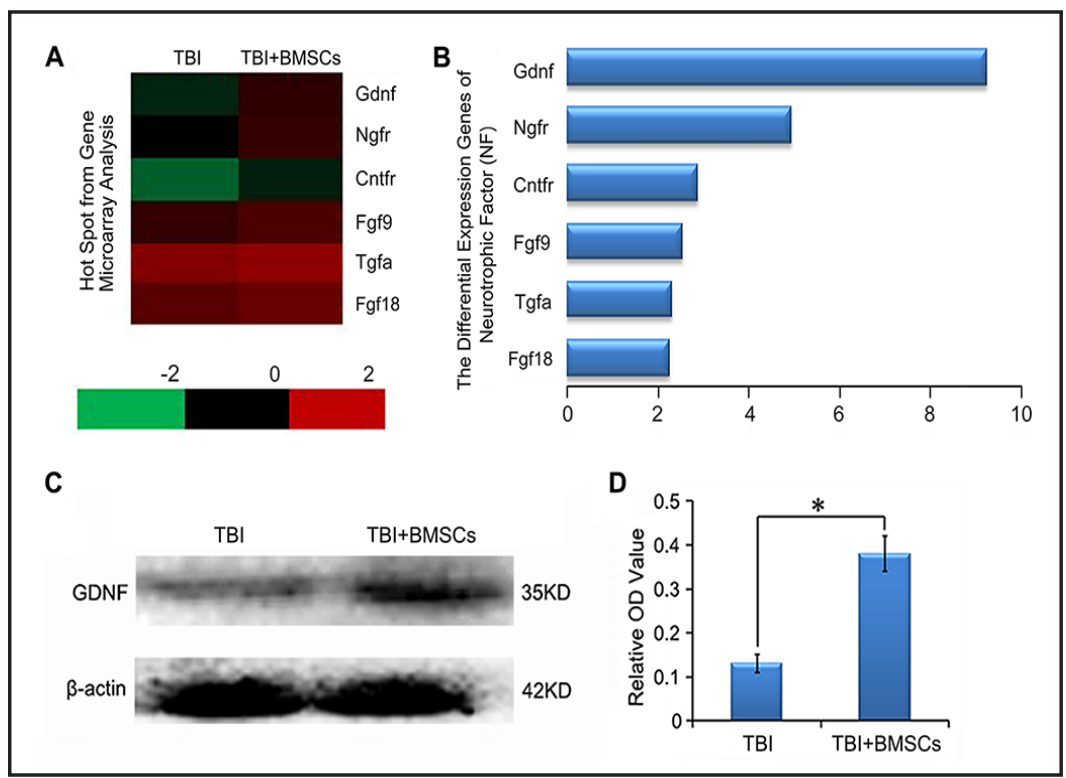

Table 3. Differential expression of NF genes in the brain of rats with TBI or TBI plus BMSC transplantation by microarray profiling

\begin{tabular}{lllll}
\hline GeneSymbol & SEQ_ID & Fold change & Fibroblast & BMSC \\
\hline Gdnf & NM_019139 & 9.217492 & 10.29883 & 94.9293831 \\
Ngfr & NM_012610 & 4.9353213 & 25.689466 & 126.7857687 \\
Cntfr & NM_001003929 & 2.8665109 & 4.9999995 & 14.332553 \\
Fgf9 & NM_012952 & 2.5270326 & 130.59972 & 330.02975 \\
Tgfa & NM_012671 & 2.3084407 & 7885.322 & 18202.79824 \\
Fgf18 & NM_019199 & 2.2502494 & 648.1227 & 1458.4377168 \\
\hline
\end{tabular}

to the results of the microarray assay, the most upregulated NF included the following: GDNF, nerve growth factor receptor (Ngfr), ciliary neurotrophic factor receptor (Cntfr), fibroblast growth factor 9 (FGF9), transforming growth factor $\alpha$ (TGF $\alpha$ ), and FGF18 (Table 3). Consistent with microarray technology findings, GDNF protein levels were significantly higher in the brains of rats with TBI plus BMSC transplantation group compared with the TBI group (Fig. 2C and D).

\section{BMSCs expressed GDNF in vitro}

To investigate the function of BMSCs expressing GDNF, GDNF immunostaining was detected in cultured BMSCs. The mRNA levels of GDNF were significantly higher in BMSCs compared with fibroblasts $(P=0.037)$ (Fig. 3A). Furthermore, the GDNF-positive immunostaining were presented in the cytoplasm of BMSCs (Fig. 3B-D). These results indicated that BMSCs could synthesize GDNF itself.

\section{Transplanted BMSCs survived and grew well in the host brain}

Fourteen days after the BMSC transplantation, a great number of green fluorescent cells could be seen in the transplanted sites, and cells had migrated around the injury site (Fig. 4A). In addition, the number of surviving cells was counted from four fields around the epicenter. The transplanted cells survived in the host (Fig. 4B). Using a Ki67 antibody as a marker of cell proliferation, it was shown that BMSCs proliferated in the host brain (Fig. 4C).

BMSC grafts increased axonal regeneration in the host brain

GAP-43 positivity is an indicator of axon regeneration [28], and synaptophysin in the synapses reflects the regeneration of synapses [29]. In this study, the number of GAP-43- 
Fig. 3. Expression of GDNF in cultured BMSCs. (A) GDNF mRNA level in cultured fibroblast cells (Fibroblast) and BMSCs cells (BMSCs) by a semi-quantitative RT-PCR method. M: Marker. (B-D) BMSCs expressed GDNF protein as indicated by immunofluorescence. Scale bars: $50 \mu \mathrm{m}$.

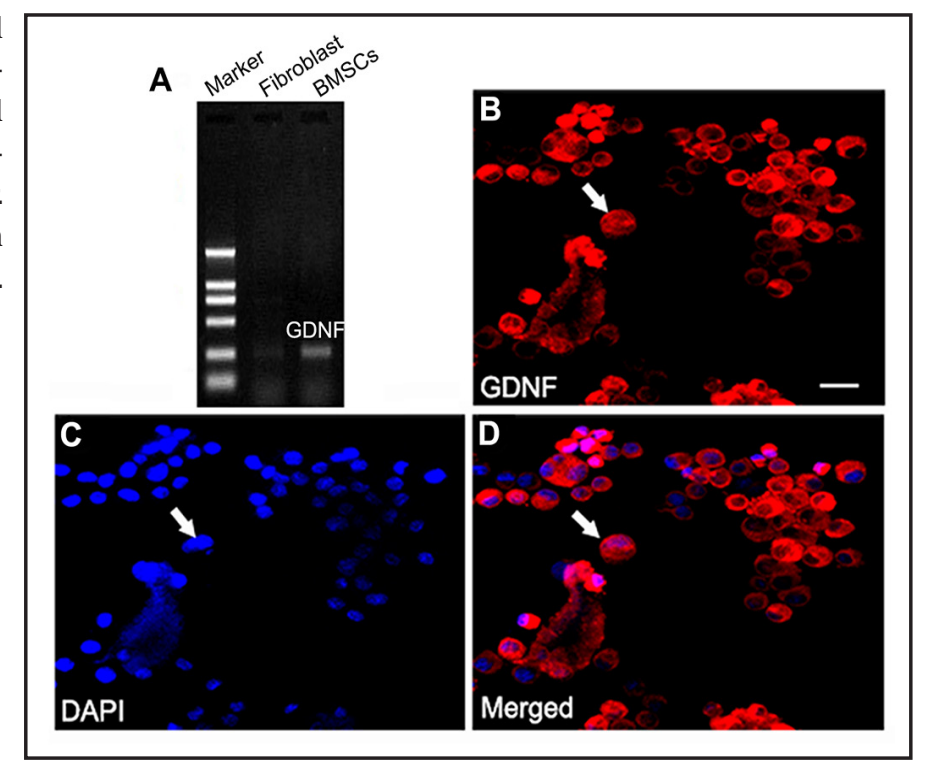

Fig. 4. Fate of BMSCs grafts in the host brain ( $\mathrm{n}=5$ per group). (A) Characterization of BMSCs harvested from green fluorescent protein-transgenic mice after being grafted in the host brain (shown as arrows). Scale bars: 50 $\mu \mathrm{m}$. (B) Proliferating cells were counted from four fields surrounding the epicenter. The transplanted cells survived in the host $(\times 200)$. (C) Ki67 was detected by immunostaining. Results showed cell proliferation from implanted cells $(\times 200)$.

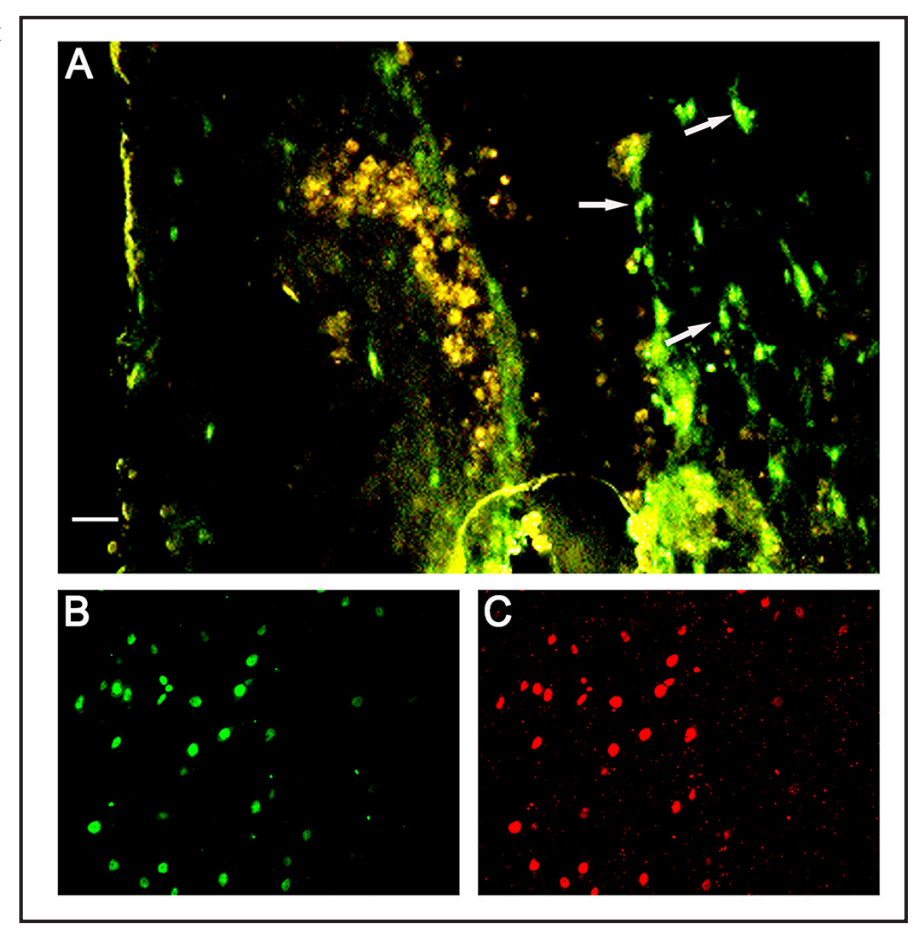

positive fibers (Fig. 5A and B) and synaptophysin-positive puncta (Fig. 5C and D) were significantly higher after BMSC transplantation compared with TBI rats $(P<0.05)$ (Fig. 5E and F).

\section{BMSC transplantation inhibited neuronal apoptosis in vivo}

TUNEL staining showed that few apoptotic cells were visible in the sham operation group (Fig. 6A), whereas obvious apoptotic cells could be detected in the TBI group (Fig. 6B), while less apoptotic cells were observed in the BMSC transplantation group (Fig. 6C). Rats with TBI showed a higher apoptosis index than rats with BMSC transplantation. TUNEL staining was replaced by PBS, shown in Fig. 6D, as a blank control. The number of apoptotic cells in sham, TBI, and BMSC transplantation groups is presented on a histogram (Fig. 6E). Compared with the TBI group, the number of apoptotic cells significantly decreased in rats after BMSC transplantation $(P<0.05)$ (Fig. 6E).

\section{KARGER}




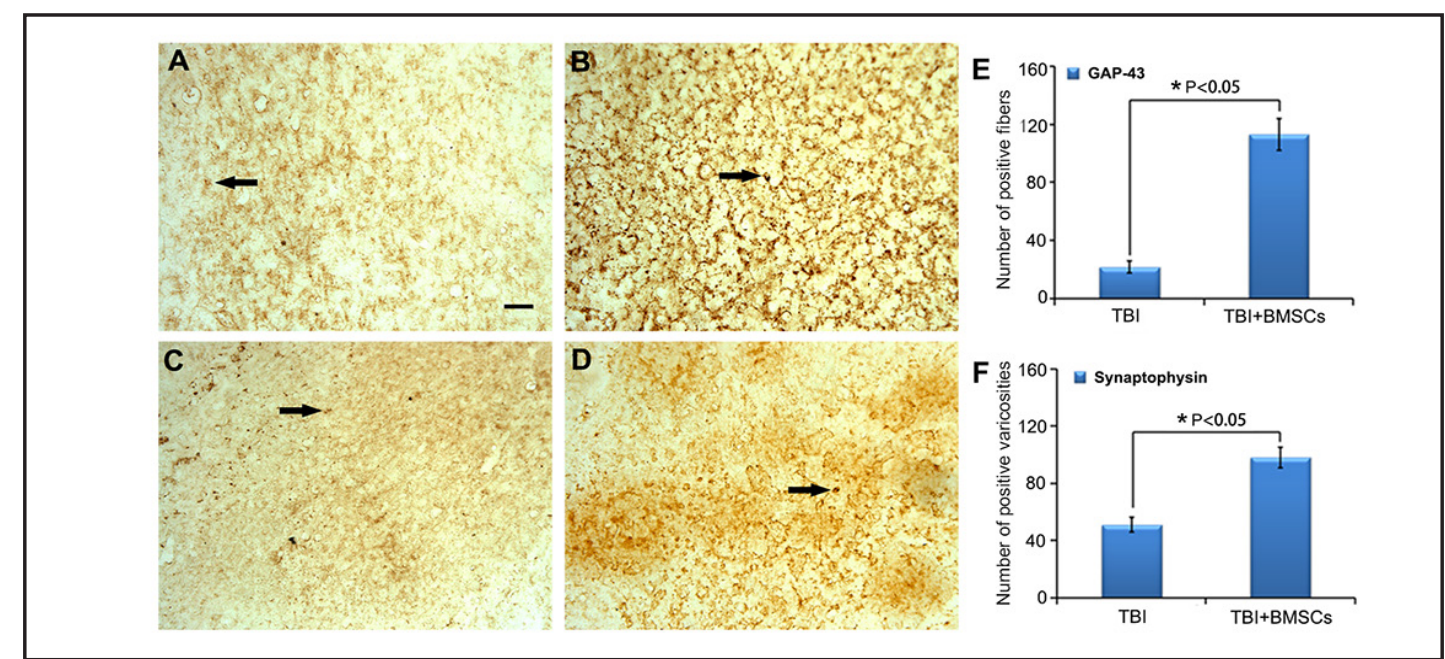

Fig. 5. Effects of BMSCs grafts on axonal regeneration in the host brain ( $n=5$ per group). (A and B) GAP-43-positive fibers (arrow) in TBI rats (A) and in TBI rats plus BMSCs transplantation (TBI + BMSCs) (B). (C and D) Synaptophysin-positive varicosities (arrow) in TBI rats (C) and in TBI rats plus BMSCs transplantation (TBI + BMSCs) (D). The number of GAP-43-positive fibers (E) and synaptophysin-positive varicosities (F) significantly increased in TBI rats plus BMSC transplantation compared to TBI rats. Scale bar: $100 \mu \mathrm{m}$.

Fig. 6. Neuronal apoptosis in the host brain ( $\mathrm{n}=5$ per group). (A) TUNEL staining showing neuronal apoptosis in the sham group. (B) TUNEL staining shows that neuronal apoptosis increased in the TBI group. (C) Transplantation of BMSCs reversed the effect on neuronal apoptosis. (D) Blank control. Scale bar: $100 \mu \mathrm{m}$. (E) Quantification of figures $A$ to $\mathrm{D}$.

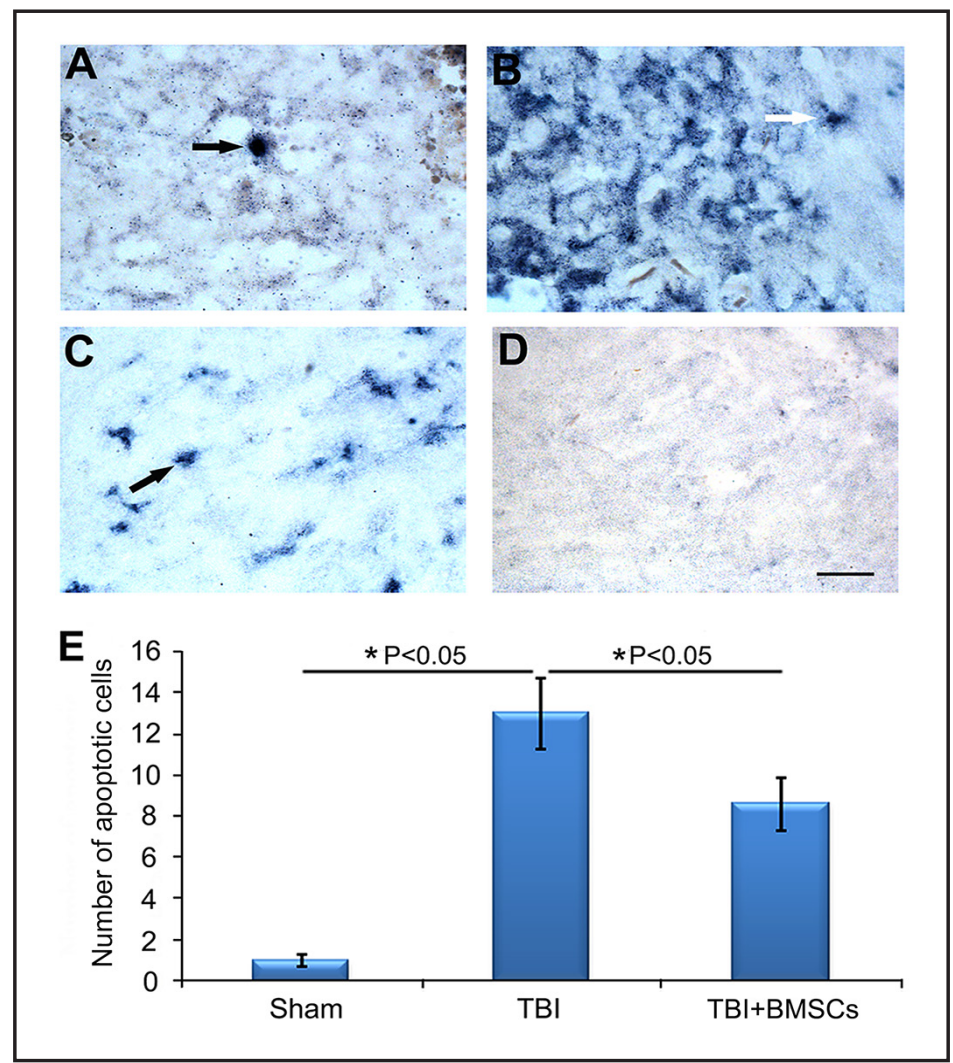

Expression of BAX and BAD decreased in the BMSC transplantation group

The Western blot analysis showed that at 14 days postoperation, TBI significantly increased the expression of both proteins in comparison to the sham group, while BMSC transplantation into injured sites reduced the protein levels of BAX and BAD compared with the TBI group $(P<0.05)$ (Fig. 7A and B).

\section{KARGER}


Fig. 7. BMSCs transplantation reduces the protein levels of BAX and BAD. (A) Western blots of the BAX and $\mathrm{BAD}$ protein expression levels in the brain tissue of rat with sham, TBI, and TBI plus BMSCs transplantation (TBI+BMSCs) groups. $\mathrm{BAX}$ and BAD protein expressions significantly decreased in BMSCs engrafted animals at 14 days postoperation (dpo). (B) Quantification of the Western blotting results revealed that $\mathrm{BAX}$ and $\mathrm{BAD}$ proteins significantly decreased in the TBI plus BMSCs transplantation group at $14 \mathrm{dpo}(P<0.05, n=9$ per group).

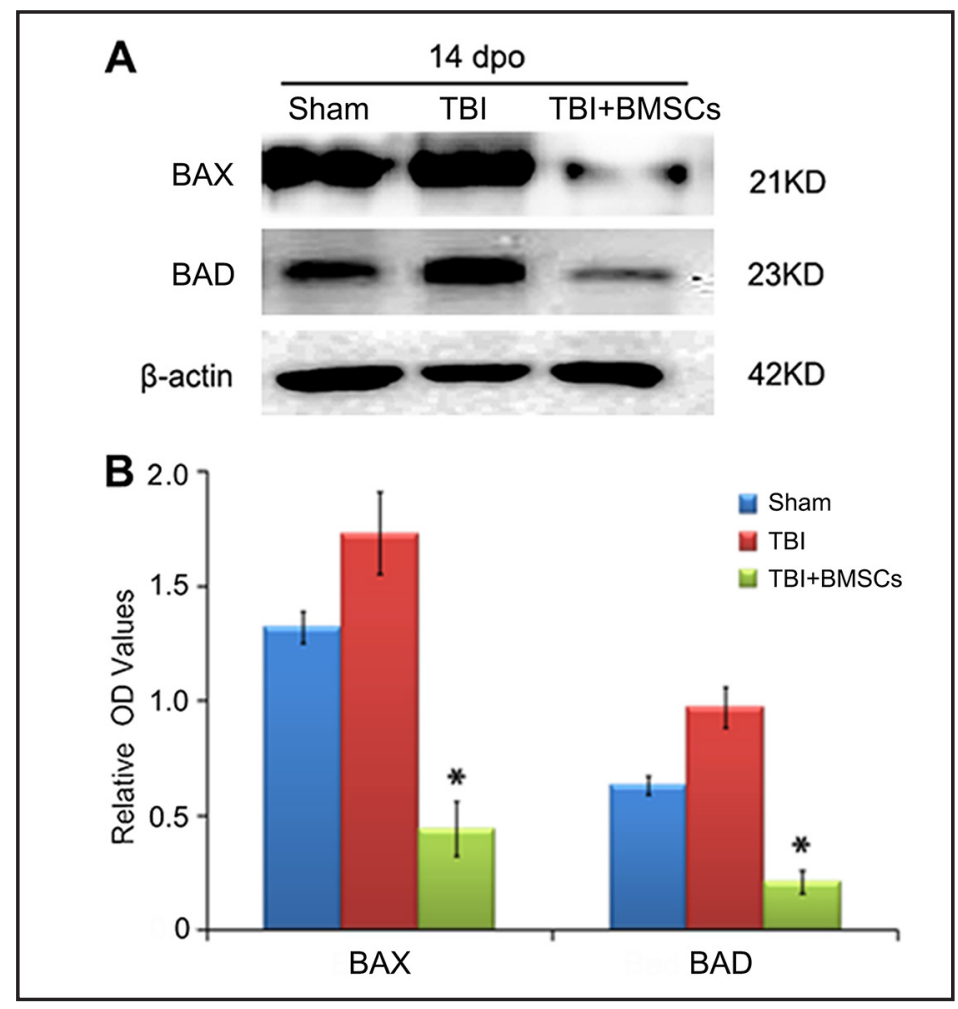

Fig. 8. Effect of BMSCs grafts in the host brain on NSS. The NSS was significantly lower in the TBI plus BMSCs transplantation group than in the TBI group $(P<0.05)$ at 7 and 14 days after transplantation. However, NSS was still higher in the TBI plus BMSCs transplantation group compared with the sham group $(P<0.05)$ at 7 and 14 days. Data are presented as mean \pm standard error ( 7 days, $n=16,13$, 15 for Sham, TBI, TBI+BMSCs, respectively; 14 days, $n=16,10,15$ for Sham, TBI, TBI+BMSCs, respectively); ${ }^{*} P<0.05$.

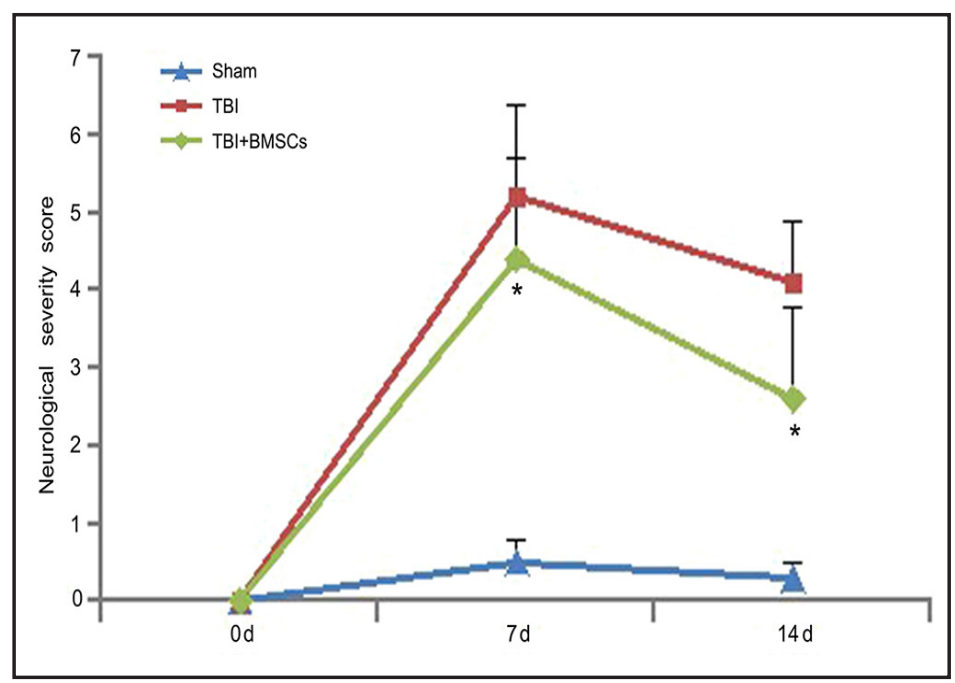

\section{BMSC transplantation decreased NSS}

As shown in Fig. 8, the changes in NSS were investigated at 7 and 14 days after BMSC transplantation. The NSS in the TBI plus BMSC group was significantly lower at $7(4.4 \pm 1.3)$ and 14 days $(2.6 \pm 1.2)$ compared with the TBI group at $7(5.2 \pm 1.2)$ and 14 days $(4.1 \pm 0.8)$ $(P<0.05)$, but was still higher than in the sham group $(P<0.05)$.

\section{Discussion}

The aim of the present study was to investigate the role of BMSCs in TBI. The results showed that BMSC transplantation could significantly improve the neurological behavior function, and that the cells migrated around the injury sites in rats with TBI. BMSC grafts resulted in an increased number of GAP-43-positive fibers and synaptophysin-positive 


\section{Cellular Physiology and Biochemistry Published online: February 15, 2016 www.karger.com/cph

Fig. 9. Possible underlying mechanism of BMSCs transplantation in improving neurological function of rats with TBI. BMSCs may release GDNF, as shown by microarray analysis and RT-PCR (Top). Then, transplanted BMSCs may suppress the expression of BAX and BAD, therefore reducing cellular apoptosis and promoting axonal regeneration and synaptic formation for functional improvement (Bottom).

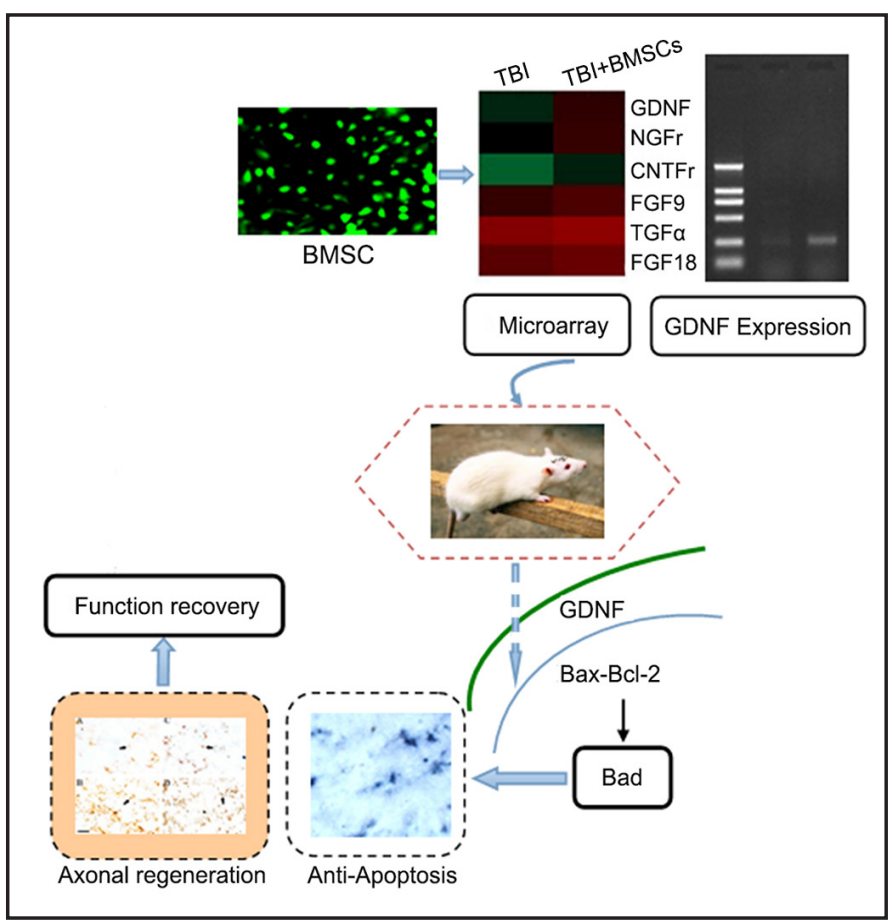

varicosities, and with suppressed apoptosis. Furthermore, microarray analysis showed that BMSCs expressed growth factors such as GDNF and NGF. The underlying mechanisms involved the induction of neuroprotection and regeneration, which could be associated with GDNF regulating the apoptosis signals through BAX and BAD. It therefore provides a new evidence to address the possibility of TBI treatments based on BMSCs implantation.

Various different cell types are currently being investigated as potential cell therapy to improve neurological function after spinal cord injury or TBI including Schwann cells, fibroblasts and mesenchymal stem cells [30-32]. Effects of BMSCs on improving neurological functions have been well studied in recent years and studies are ongoing into methods of increasing their viability after transplant [33,34]. BMSCs promote remyelination and accelerate conductive velocity of electrophysiology of demyelinated nerves [35]. Once BMSCs encounter astrocytes, the structure of astrocytes changes and they form a channel that is useful to regenerate axons through the glial scars. As a result, functional connections are possible [36, 37].

When systemically administered, BMSCs migrate toward the sites of brain injury and respond to the TBI brain environment. BMSCs include stem cells and progenitor cells, which act like small factories to produce a set of neurotrophins and growth factors including BDNF, bFGF, and NGF. These neurotrophins and growth factors are important for neuronal survival and axonal growth [38]. Among these factors, GDNF, as an optimal growth factor, can decrease the number of apoptotic cells and maintain neuronal survival [15]. Therefore, GDNF should be useful to reverse neuronal fate under the injured condition. In the present study, our microarray assay and Western blot data revealed that GDNF mRNA and protein levels were increased after BMSCs injection into the pericontusional brain tissue. A previous study has reported that co-expression of GDNF with GFRalpha1 in neural progenitor cells increases their expression of neuronal markers [39]. All these results suggest that GDNF released from BMSCs may be a critical factor for neural remodeling after injury.

$\mathrm{BAX}$, as an inducer of programmed cell death, has the ability to bind to the anti-apoptotic protein BCL-2. BAD is a member of the BCL-2 gene family, which encodes both inducers and inhibitors of programmed cell death. Therefore, BAX plays its role in physiological or pathological process via BCL-2 [40-42]. Inhibitors of programmed cell death include BCL$2[43,44]$ and BCL-XL [45]. The inducers of programmed cell death include BAX, BAK, and BCL-XS $[26,45-48]$. These proteins have been shown to form a network of homo- and KARGER 


\section{Cellular Physiology Cell Physiol Biochem 2016;38:748-762 \begin{tabular}{ll|l} 
DOI: 10.1159/000443031 & O 2016 The Author(s). Published by S. Karger AG, Basel \\
www.karger.com/cpb
\end{tabular} \\ Shen et al.: BMSCs Promote Neuronal Restoration in Rats}

heterodimers to induce apoptosis [49]. The BCL-2 activity is correlated with the ability to form heterodimers with BAX [50], but is BCL-XL independent [51]. Furthermore, BAX is involved in several NF-mediated neuroprotective effects and has an anti-apoptosis role, which also involves GDNF [52], BDNF [53], and NT3 [54]. In the present study, the rat brains that had BMSC transplantation showed decreased expression of BAX and BAD and increased GDNF protein level. These results suggested that GDNF released from BMSCs plays a role in neural remodeling possibly via suppressing the BAX/BAD pathway.

The present study mainly shows that GDNF may be a vital molecule in TBI following BMSC transplantation, and BMSCs regulated the expression of BAX and BAD (the possible underlying mechanism is presented in Fig. 9). BAX was originally identified as a major inducer of immune and inflammatory responses under injury conditions. Transgenic mice overexpressing BAX display gliosis, neuronal cell loss, and learning disabilities with prominent neurodegeneration [54]. Hence, excessive BAX expression is likely to play a fundamental role in the pathogenesis of the undesirable outcomes of TBI. In addition, BAD, as a proapoptotic protein in the mitochondria-mediated apoptosis pathway [54,55], was also involved in the GDNF-mediated anti-apoptosis in response to BMSC transplantation. In the present study, the BAD expression was significantly downregulated after co-transplantation with BMSCs. This could certainly lead to reduced apoptotic activity. Hence, the prevention of cell apoptosis by the GDNF could be dependent on BAD regulation, a crucial apoptosis signal molecule. Otherwise, the apoptotic activity of BAD is dependent on its phosphorylation status. When BAD is phosphorylated, it forms a complex protein that cannot induce apoptosis [56]. Recent data demonstrated that BMSCs increased astrocyte survival via stimulation of phosphoinositide-3 kinase (PI3K)/Akt and mitogen-activated protein kinase/extracellular signal-regulated kinase (MAPK/Erk1,2) pathways [57]. Therefore, the effects of GDNF on the phosphorylation of BAD and more proteins and pathways involved in apoptosis need further study in the future, for example, caspase 3, caspase 9a, PI3K/Akt, and ERK1/2.

The present study is not without limitations. Indeed, the study was performed in animals, and the results are not yet directly applicable to humans. Only a few genes and proteins were examined, and more comprehensive studies are necessary. Although GDNF levels produced by BMSCs in brain were measured, the mechanisms underlying BMSCs improving TBI injury were not investigated; the effects of NTFs should be impeded to demonstrate their participation in the protective mechanism in further study. Given that the immune response is also likely to be critical to the mechanism of BMSCs transplantation improving neurological deficits; the influence of an immunosuppressive regime on the rats should be considered in future studies.

In conclusion, BMSC transplantation improved the neurological deficits and enhanced neuronal survival and axonal regeneration in rats after TBI. The underlying molecular mechanisms may be related to the downregulation of BAX and BAD, which might be associated with increased GDNF expression from transplanted BMSCs in the host brain. The present study provides important morphological and molecular biological evidence for TBI in favor of using BMSC transplantation for TBI treatment.

\section{Acknowledgments}

This study was supported by the Natural Science Fund of Yunnan Province (No. 2010ZC109) by a grant from the China Nation Science Foundation (No. 81271358, 81070991, and 81260191) and the Key Natural Science Fund of Yunnan Province (No. 2012ZC107).

\section{Disclosure Statement}

The authors declare that they have no conflict of interest. 


\section{Cellular Physiology Cell Physiol Biochem 2016;38:748-762

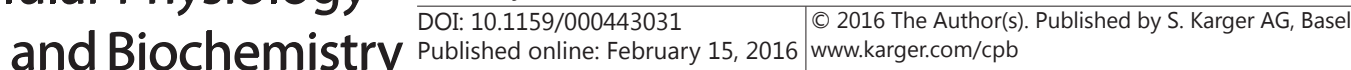 \\ Shen et al: BMSCs Promote Neuronal Restoration in Rats}

\section{References}

1 Wu X, Hu J, Zhuo L, Fu C, Hui G, Wang Y, Yang W, Teng L, Lu S, Xu G: Epidemiology of traumatic brain injury in eastern China, 2004: a prospective large case study. J Trauma 2008;64:1313-1319.

2 Amaranath JE, Ramanan M, Reagh J, Saekang E, Prasad N, Chaseling R, Soundappan S: Epidemiology of traumatic head injury from a major paediatric trauma centre in New South Wales, Australia. ANZ J Surg 2014;84:424-428.

3 Chadbunchachai W, Suphanchaimaj W, Settasatien A, Jinwong T: Road traffic injuries in Thailand: current situation. J Med Assoc Thai 2012;95:S274-281.

4 Kumar A, Loane DJ: Neuroinflammation after traumatic brain injury: opportunities for therapeutic intervention. Brain Behav Immun 2012;26:1191-1201.

5 Kernie SG, Erwin TM, Parada LF: Brain remodeling due to neuronal and astrocytic proliferation after controlled cortical injury in mice. J Neurosci Res 2001;66:317-326.

6 Schwab ME: Repairing the injured spinal cord. Science 2002;295:1029-1031.

7 Kanelos SK, McDeavitt JT: Neural transplantation: potential role in traumatic brain injury. J Head Trauma Rehabil 1998;13:1-9.

8 Mahmood A, Lu D, Yi L, Chen JL, Chopp M: Intracranial bone marrow transplantation after traumatic brain injury improving functional outcome in adult rats. J Neurosurg 2001;94:589-595.

9 Fairless R, Barnett SC: Olfactory ensheathing cells: their role in central nervous system repair. Int J Biochem Cell Biol 2005;37:693-699.

10 Wei L, Fraser JL, Lu ZY, Hu X, Yu SP: Transplantation of hypoxia preconditioned bone marrow mesenchymal stem cells enhances angiogenesis and neurogenesis after cerebral ischemia in rats. Neurobiol Dis 2012;46:635-645.

11 Ding P, Yang Z, Wang W, Wang J, Xue L: Transplantation of bone marrow stromal cells enhances infiltration and survival of CNP and Schwann cells to promote axonal sprouting following complete transection of spinal cord in adult rats. Am J Transl Res 2014;6:224-235.

12 Li C, Zheng Y, Wang X, Xia W, Gao H, Li D, Ma X: Bone marrow-derived stem cells contribute skin regeneration in skin and soft tissue expansion. J Cell Physiol 2011;226:2834-2840.

13 Ban DX, Ning GZ, Feng SQ, Wang Y, Zhou XH, Liu Y, Chen JT: Combination of activated Schwann cells with bone mesenchymal stem cells: the best cell strategy for repair after spinal cord injury in rats. Regen Med 2011;6:707-720.

14 Naghdi M, Tiraihi T, Mesbah-Namin SA, Arabkheradmand J: Induction of bone marrow stromal cells into cholinergic-like cells by nerve growth factor. Iran Biomed J 2009;13:117-123.

15 Jiang Y, Lv H, Huang S, Tan H, Zhang Y, Li H: Bone marrow mesenchymal stem cells can improve the motor function of a Huntington's disease rat model. Neurol Res 2011;33:331-337.

16 Shichinohe H, Ishihara T, Takahashi K, Tanaka Y, Miyamoto M, Yamauchi T, Saito H, Takemoto H, Houkin $\mathrm{K}$, Kuroda S: Bone marrow stromal cells rescue ischemic brain by trophic effects and phenotypic change toward neural cells. Neurorehabil Neural Repair 2015;29:80-89.

17 Guo X, Liu W, Pan Y, Ni P, Ji J, Guo L, Zhang J, Wu J, Jiang J, Chen X, Cai Q Li J, Zhang J, Gu Q, Liu B, Zhu Z, Yu Y: Homeobox gene IRX1 is a tumor suppressor gene in gastric carcinoma. Oncogene 2010;29:3908-3920.

18 Yang JD, Cheng H, Wang JC, Feng XM, Li YN, Xiao HX: The isolation and cultivation of bone marrow stem cells and evaluation of differences for neural-like cells differentiation under the induction with neurotrophic factors. Cytotechnology 2014;66:1007-1019.

19 Boxall SA, Jones E: Markers for characterization of bone marrow multipotential stromal cells. Stem Cells Int 2012;2012:975871.

20 Turkoglu OF, Eroglu H, Okutan O, Gurcan O, Bodur E, Sargon MF, Oner L, Beskonakl i E: Atorvastatin efficiency after traumatic brain injury in rats. Surg Neurol 2009;72:146-152; discussion 152.

21 Harting MT, Sloan LE, Jimenez F, Baumgartner J, Cox CS Jr. Subacute neural stem cell therapy for traumatic brain injury. J Surg Res 2009;153:188-194.

22 Sandner B, Ciatipis M, Motsch M, Soljanik I, Weidner N, Blesch A: Limited functional effects of subacute syngeneic bone marrow stromal cell transplantation after rat spinal cord contusion injury. Cell Transplant 2016;25:125-139. 


\section{Cellular Physiology Cell Physiol Biochem 2016;38:748-762

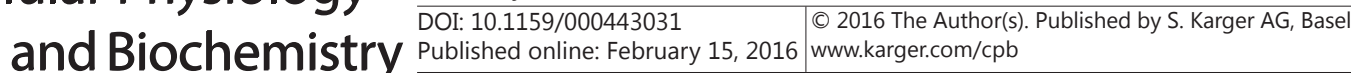 \\ Shen et al.: BMSCs Promote Neuronal Restoration in Rats}

23 Lukashyk SP, Tsyrkunov VM, Isaykina YI, Romanova ON, Shymanskiy AT, Aleynikova OV, Kravchuk RI: Mesenchymal Bone Marrow-derived Stem Cells Transplantation in Patients with HCV Related Liver Cirrhosis. J Clin Transl Hepatol 2014;2:217-221.

24 Hirjak D, Wolf RC, Stieltjes B, Hauser T, Seidl U, Thiemann U, Schroder J, Thomann PA: Neurological soft signs and brainstem morphology in first-episode schizophrenia. Neuropsychobiology 2013;68:91-99.

25 Loncarevic-Vasiljkovic N, Pesic V, Todorovic S, Popic J, Smiljanic K, Milanovic D, Ruzdijic S, Kanazir S: Caloric restriction suppresses microglial activation and prevents neuroapoptosis following cortical injury in rats. PLoS One 2012;7:e37215.

26 Charriaut-Marlangue C, Ben-Ari Y: A cautionary note on the use of the TUNEL stain to determine apoptosis. Neuroreport 1995;7:61-64.

27 Sobrado M, Lopez MG, Carceller F, Garcia AG, Roda JM: Combined nimodipine and citicoline reduce infarct size, attenuate apoptosis and increase bcl-2 expression after focal cerebral ischemia. Neuroscience 2003;118:107-113.

28 Schaden H, Stuermer CA, Bahr M: GAP-43 immunoreactivity and axon regeneration in retinal ganglion cells of the rat. J Neurobiol 1994;25:1570-1578.

29 Yang H, Standifer KM, Sherry DM: Synaptic protein expression by regenerating adult photoreceptors. J Comp Neurol 2002;443:275-288.

30 Yang L, Ge Y, Tang J, Yuan J, Ge D, Chen H, Zhang H, Cao X: Schwann Cells Transplantation Improves Locomotor Recovery in Rat Models with Spinal Cord Injury: a Systematic Review and Meta-Analysis. Cell Physiol Biochem 2015;37:2171-2182.

31 Chang Y, Li H, Guo Z: Mesenchymal stem cell-like properties in fibroblasts. Cell Physiol Biochem 2014;34:703-714.

32 Bader AM, Brodarac A, Klose K, Bieback K, Choi YH, Kang KS, Kurtz A, Stamm C: Cord blood mesenchymal stromal cell-conditioned medium protects endothelial cells via STAT3 signaling. Cell Physiol Biochem 2014;34:646-657.

33 Sun Y, Li QF, Yan J, Hu R, Jiang H: Isoflurane Preconditioning Promotes the Survival and Migration of Bone Marrow Stromal Cells. Cell Physiol Biochem 2015;36:1331-1345.

34 Wu J, Niu J, Li X, Li Y, Wang X, Lin J, Zhang F: Hypoxia induces autophagy of bone marrow-derived mesenchymal stem cells via activation of ERK1/2. Cell Physiol Biochem 2014;33:1467-1474.

35 Osanai T, Kuroda S, Sugiyama T, Kawabori M, Ito M, Shichinohe H, Kuge Y, Houkin K, Tamaki N, Iwasaki Y: Therapeutic effects of intra-arterial delivery of bone marrow stromal cells in traumatic brain injury of rats--in vivo cell tracking study by near-infrared fluorescence imaging. Neurosurgery 2012;70:435-444; discussion 444.

36 Gu W, Zhang F, Xue Q Ma Z, Lu P, Yu B: Transplantation of bone marrow mesenchymal stem cells reduces lesion volume and induces axonal regrowth of injured spinal cord. Neuropathology 2010;30:205-217.

37 Shen LH, Li Y, Chopp M: Astrocytic endogenous glial cell derived neurotrophic factor production is enhanced by bone marrow stromal cell transplantation in the ischemic boundary zone after stroke in adult rats. Glia 2010;58:1074-1081.

38 Gu W, Zhang F, Xue Q, Ma Z, Lu P, Yu B: Bone mesenchymal stromal cells stimulate neurite outgrowth of spinal neurons by secreting neurotrophic factors. Neurol Res 2012;34:172-180.

39 Nojiri Y, Takeda S, Enomoto M, Nishitsuji H, Masuda T, Sotome S, Shinomiya K: Co-overexpression of GDNF and GFRalpha1 induces neural differentiation in neural progenitor cells in comparison to bone marrow stromal cells. J Med Dent Sci 2008;55:121-128.

40 Korsmeyer SJ: Bcl-2 initiates a new category of oncogenes: regulators of cell death. Blood 1992;80:879886.

41 Reed JC: Bcl-2 and the regulation of programmed cell death. J Cell Biol 1994;124:1-6.

42 Thompson CB: Apoptosis in the pathogenesis and treatment of disease. Science 1995;267:1456-1462.

43 Tsujimoto Y, Croce CM: Analysis of the structure, transcripts, and protein products of bcl-2, the gene involved in human follicular lymphoma. Proc Natl Acad Sci USA 1986;83:5214-5218.

44 Sentman CL, Shutter JR, Hockenbery D, Kanagawa O, Korsmeyer SJ: bcl-2 inhibits multiple forms of apoptosis but not negative selection in thymocytes. Cell 1991;67:879-888. 


\section{Cellular Physiology Cell Physiol Biochem 2016;38:748-762

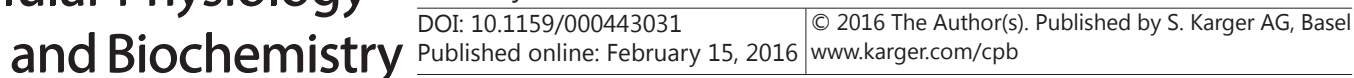 \\ Shen et al.: BMSCs Promote Neuronal Restoration in Rats}

45 Boise LH, Gonzalez-Garcia M, Postema CE, Ding L, Lindsten T, Turka LA, Mao X, Nunez G, Thompson CB: bcl-x, a bcl-2-related gene that functions as a dominant regulator of apoptotic cell death. Cell 1993;74:597608.

46 Oltvai ZN, Milliman CL, Korsmeyer SJ: Bcl-2 heterodimerizes in vivo with a conserved homolog, Bax, that accelerates programmed cell death. Cell 1993;74:609-619.

47 Farrow SN, White JH, Martinou I, Raven T, Pun KT, Grinham CJ, Martinou JC, Brown R: Cloning of a bcl-2 homologue by interaction with adenovirus E1B 19K. Nature 1995;374:731-733.

48 Kiefer MC, Brauer MJ, Powers VC, Wu JJ, Umansky SR, Tomei LD, Barr PJ: Modulation of apoptosis by the widely distributed Bcl-2 homologue Bak. Nature 1995;374:736-739.

49 Oltvai ZN, Korsmeyer SJ: Checkpoints of dueling dimers foil death wishes. Cell 1994;79:189-192.

50 Yin XM, Oltvai ZN, Korsmeyer SJ: BH1 and BH2 domains of Bcl-2 are required for inhibition of apoptosis and heterodimerization with Bax. Nature 1994;369:321-323.

51 Cheng EH, Levine B, Boise LH, Thompson CB, Hardwick JM: Bax-independent inhibition of apoptosis by BclXL. Nature 1996;379:554-556.

52 Bar-Am O, Weinreb 0, Amit T, Youdim MB: Regulation of Bcl-2 family proteins, neurotrophic factors, and APP processing in the neurorescue activity of propargylamine. FASEB J 2005;19:1899-1901.

53 Patel TD, Kramer I, Kucera J, Niederkofler V, Jessell TM, Arber S, Snider WD: Peripheral NT3 signaling is required for ETS protein expression and central patterning of proprioceptive sensory afferents. Neuron 2003;38:403-416.

54 Shintani A, Nakao N, Kakishita K, Itakura T: Protection of dopamine neurons by bone marrow stromal cells. Brain Res 2007;1186:48-55.

55 Chen CJ, Ou YC, Liao SL, Chen WY, Chen SY, Wu CW, Wang CC, Wang WY, Huang YS, Hsu SH: Transplantation of bone marrow stromal cells for peripheral nerve repair. Exp Neurol 2007;204:443-453.

56 Gao YJ, Qian W, Wang BH, Lin R, Hou XH: Differentiation potential of bone marrow stromal cells to enteric neurons in vitro. Chin J Dig Dis 2006;7:156-163.

57 Gao Q Li Y, Chopp M: Bone marrow stromal cells increase astrocyte survival via upregulation of phosphoinositide 3-kinase/threonine protein kinase and mitogen-activated protein kinase kinase/ extracellular signal-regulated kinase pathways and stimulate astrocyte trophic factor gene expression after anaerobic insult. Neuroscience 2005;136:123-134. 